\title{
Implementasi Case Based Reasoning pada Sistem Identifikasi Kerusakan Komputer dengan Metode Similaritas Simple Matching Coefficient
}

\author{
Made Hanindia Prami Swari ${ }^{1}$, Jannatul Firdaus ${ }^{2}$ \\ ${ }^{1,2}$ Program Studi Informatika, Universitas Pembangunan Nasional "Veteran” Jawa Timur \\ ${ }^{3}$ jannatulfirdaus 015 @gmail.com \\ *Corresponding author email: madehanindia.fik@upnjatim.ac.id
}

\begin{abstract}
Abstrak- Komputer merupakan sebuah perangkat cerdas digital yang menjadi kebutuhan primer baik di lingkungan perusahaan maupun personal. Sebuah perangkat elektronik tentunya tidk dapat dihindarkan dari kemungkinan kerusakan. Kerusakan perangkat komputer merupakan hal yang sangat sering terjadi, baik kerusakan ringan yang dapat diperbaiki sendiri maupun kerusakan berat yang memerlukan maintenance dari pihak lain. Pengguna komputer pun bukan melulu dari kalangan IT yang sudah familiar dengan troubleshoting sehingga akan mengalami kesulitan jika perangkat komputernya mengalami permasalahan, walaupun permasalahan yang terjadi hanya permasalahan ringan. Banyaknya jumlah data kasus permasalahan yang sering dialami oleh pengguna komputer tentang kerusakan komputer yang memiliki gejala kerusakan berbeda antar satu kasus dengan kasus lainnya yang didapat dari berbagai sumber, hal ini memungkinkan pengimplementasian sebuah sistem cerdas menggunakan penalaran berbasis kasus atau yang dikenal dengan case based reasoning. Penelitian ini dilakukan dengan pengumpulan kasus untuk diisikan pada basis kasus, perhitungan kemiripan kasus menggunakan Simple Matching Coeficient, serta merekomendasikan hasil diagnosis berdasarkan nilai kemiripan kasus. Hasil dari penelitian ini menunjukkan bahwa telah berhasil dibangun sebuah sistem komputer menggunakan pendekatan penalaran berbasis kasus pendeteksi kerusakan awal pada komputer.
\end{abstract}

Kata Kunci-Case based reasoning, Kasus, SMC, Similaritas

\section{Pendahuluan}

Keberadaan komputer saat ini sudah merambah ke segala lini kehidupan, hal ini menyebabkan pekerjaan manusia menjadi lebih ringan karena keberadaannya [1]. Dengan komputer manusia sangat terbantu dalam melakukan pekerjaannya, namun pekerjaan tersebut akan terganggu jika komputer yang digunakan untuk meringankan kerja manusia terdapat masalah maupun kerusakan.

Komputer merupakan sebuah perangkat cerdas digital yang menjadi kebutuhan primer baik di lingkungan perusahaan maupun personal. Sebuah perangkat elektronik tentunya tidk dapat dihindarkan dari kemungkinan kerusakan. Kerusakan perangkat komputer merupakan hal yang sangat sering terjadi, baik kerusakan ringan yang dapat diperbaiki sendiri maupun kerusakan berat yang memerlukan maintenance dari pihak lain. Pengguna komputer pun bukan melulu dari kalangan IT yang sudah familiar dengan troubleshoting sehingga akan mengalami kesulitan jika perangkat komputernya mengalami permasalahan, walaupun permasalahan yang terjadi hanya permasalahan ringan. Kerusakan komputer secara umum dikelompokkan menjadi 2 kategori yaitu kerusakan hardware dan kerusakan software. Seringkalai masalah yang muncul pada hardware dikarenakan penggunaan perangkat yang sudah cukup lama, naik turunnya tegangan listrik, pemakaian yang tidak sesuai, serta kecerobohan yang tidak disengaja. Bagi orang awam, kerusakan komputer akan menjadi suatu masalah tersendiri karena akan langsung meminta bantuan teknisi, padahal seringkali kerusakan yang terjadi merupakan kerusakan kecil yang dapat diperbaiki sendiri [2].

Banyaknya jumlah data kasus permasalahan yang sering dialami oleh pengguna komputer tentang kerusakan komputer yang memiliki gejala kerusakan berbeda antar satu kasus dengan kasus lainnya yang didapat dari berbagai sumber, hal ini memungkinkan pengimplementasian sebuah sistem cerdas menggunakan penalaran berbasis kasus atau yang dikenal dengan Case based reasoning (CBR). CBR merupakan sebuah metode pemecahan masalah yang menggunakan penelaran berbasis kasus atau pengalaman yang telah terjadi sebelumnya di masa lampau [3]. Telah banyak dilakukan penelitian yang menggunakan pendekatan CBR dan menghasilkan hasil penelitian yang akurat pada berbagai bidang [1].

Dengan banyaknya pengguna awam yang tidak memiliki pengetahuan dalam mengidentifikasi dan mengatasi kerusakan terhadap komputer, para pengguna akan memilih mengeluarkan biaya untuk mengatasi kerusakan tersebut dengan menservice komputer ke teknisi yang ahli dibidangnya. Berdasarkan dari masalah tersebut, maka dilakukan penelitian untuk mengimplementasikan Case based reasoning pada Sistem Identifikasi Kerusakan Komputer dengan Metode Simple Matching Coefficient Similarity yang diharapkan dapat membantu pengguna komputer mengidentifikasi dan mengatasi kerusakan berdasarkan gejala pada komputer pengguna tanpa mengeluarkan biaya yang cukup banyak dengan menggunakan sistem tersebut.

Beberapa penliti sebelumnya telah melakukan penelitian terkait deteksi kerusakan laptop ataupn komputer khususnya menggunakan pendekatan penalaran berbasis kasus, seperti yang dilakukan oleh Agustinus pada tahun 2018 yang menggunakan metode nearest neighbor dalam proses retrievalnya [4], serta Annisa, dkk pada tahun 2017 dengan 
menggunakan metode similaritas Jaccard Coeficient [2] Penelitian ini dilakukan menggunakakan metode similaritas yang berbeda, yakni metode Simple Matching Coeficient karena berdasarkan penelitian yang dilakukan oleh Filiyensi tahun 2018 menyatakan bahwa metode SMC memberikan akurasi yang baik dibandingkan metode Jaccard Coeficient [5]

\section{TinjauAn PUSTAKA}

Penelitian ini menggunakan beberapa teori dalam penyelesaiannya. Teori-teori tersebut diantaranya terkait Case based reasoning, Simple Matching Coeficient, serta jenis kerusakan komputer.

\section{A. Case Based Reasoning}

Konsep dasar dari pendekatan berbasis CBR adalah mencari kemiripan kasus saat ini dengan kasus-kasus berdasarkan pengalaman pada masa lampau. Hal ini didasarkan pada hipotesis bahwa kasus baru memiliki kesimpulan yang sama dengan kasus lama yang memiliki karakteristik yang sama [6]. Metode CBR sudah lama diteliti oleh banyak peneliti sebelumnya, penetahuan ini ditemukan dan diteliti secara berkesinambungan oleh Roger Schank bersama rekan-rekannya di Universitas Yale sekitar tahun 1980.

Metode CBR merupakan sistem rekomendasi berbasis pengetahuan atau yang lebih dikenal dengan sebutan Knowledge Based Recommendation System (KBRS). Secara umum metode KBRS menggunakan pola pengetahuan untuk memberikan hasil rekomendasi. Hal terpenting dalam KBRS adalah membangun basis pengetahuan dan cara merepresentasikan pengetahuan tersebut sehingga dapat dipahami oleh sistem [7].

\section{Siklus CBR}

Terdapat 4 langkah yang dapat dilakukan pada satu siklus sistem CBR. Keempat langkah tersebut dapat terlihat pada Gbr. 1.

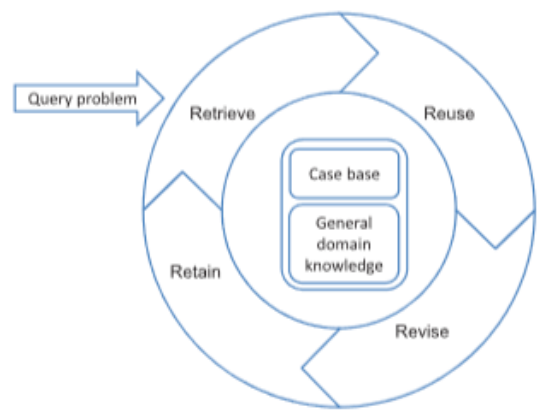

Gbr 1. Siklus CBR (berdasarkan Aamodt dan Plaza [8])

Keterangan :

1. Retrieve, mencari kasus-kasus pada basis kasus yang memiliki nilai similaritas dengan kasus baru.
2. Reuse, mengambil solusi dari kasus lama yang memiliki nilai similaritas terbesar dengan kasus baru sebagai solusi dari kasus baru.

3. Revise, melakuka penyesuaian atau revisi terhadap solusi dari kasus lama apabila diperlukan.

4. Retain, memasukkan kasus baru kedalam basis kasus untuk menambah pengetahuan sistem [2].

\section{B. Simple Matching Coefficient (SMC)}

Simple Matching Coefficient (SMC) merupakan salah satu metode komputasi yang dapat digunakan dalam mencari kecekatan (similaritas) antar dua objek. Karakteristik dari metode ini adalah objek yang digunakan harus bersifat biner. Nilai 0 menunjukkan tidak terdapat gejala, sebaliknya nilai 1 mengindikasikan terdapat gejala. Setiap fitur atau gejala akan diberi pembobotan dari pakar [6].

Pada penelitian ini, metode SMC diguakan untuk mencari nilai kedekatan antar gejala-gejala yang terdapat pada kasus baru dengan fitur-fitur yang dimiliki pada setiap kasus yang teah tersimpan pada basis kasus. Adapaun persamaan 1 menunjukkan persamaan yang digunakan untuk mencari kedekatan antara kasus baru dengan kasus yang telah tersimpan pada basis kasus [9] :

$$
\operatorname{SMC}(\mathrm{X}, \mathrm{Y})=\frac{M_{11}+M_{00}}{M_{10}+M_{01}+M_{11}+M_{00}}
$$

Keterangan :

$\mathrm{X}=$ Kasus pada basis kasus yang diuji

$\mathrm{Y}=$ Kasus yang akan dihitung similaritasnya

M11= Jumlah gejala saat X bernilai 1 dan Y bernilai 1

M10 = Jumlah gejala saat X bernilai 1 dan $Y$ bernilai 0

$\mathrm{M} 01=$ Jumlah gejala saat $\mathrm{X}$ bernilai 0 dan $\mathrm{Y}$ bernilai 1

$\mathrm{M} 00=$ Jumlah gejala saat $\mathrm{X}$ bernilai 0 dan $\mathrm{Y}$ bernilai 0

Kasus baru diklasifikasikan memiliki kemiripan sebesar $100 \%$ dengan kasus pada basis kasus apabila nilai similaritas dari SMC (X,Y) sama dengan 1, sedangkan tidak similar apabila nilai SMC $(\mathrm{X}, \mathrm{Y})$ sama dengan 0 .

\section{Jenis Kerusakan Komputer}

Kerusakan komputer sangat bermacam-macam, mulai dari kerusakan hardware maupun softwarenya. Jenis kerusakan pada komputer yang sering terjadi antara lain :

1. Kerusakan Chipset/VGA

Gejala gangguan :

a. Layar tidak tampil

b. Layar putih

c. Garis garis warna tidak beraturan

2. Kerusakan Harddisk

Gejala ganggunan :

a. Laptop Berasa lambat

b. Data file mengalami kerusakan

c. tidak mau booting

d. Mengalami blu screen

e. tidak masuk windows 
3. Kerusakan Motheboard

Gejala gangguan :

a. dihidupkan agak sulit

b. Baterai tidak mau dicharge

c. Mati Total

d. Indikator Charger menyala, setelah dicharger lampu indikator pada charge mati

4. Kerusakan Keyboard

Gejala gangguan :

a. Keyboard belum terpasang dengan benar

b. Beberapa tuts tidak berfungsi

c. Kursor berjalan tidak stabil/gerak sendiri

5. Kerusakan Memory RAM

Gejala gangguna :

a. pada saat dihudupkan tidak tampak tampilan sama sekali

b. Blu screen pada saat mulai loading OS

c. Keluar suara beep berulang

\section{Representasi Kasus}

Dalam melakukan penelitian dengan Case Base Reasoning, basis kasus sangat berpengaruh penting dalam mengolah data tergantung pada struktur dan isi dari koleksi kasus. Pada penelitian ini Data Kerusakan komputer didapat dari situs website yang mememiliki data mengenai macammacam kerusakan. Data-data yang diperoleh terdiri dari data:

1. Jenis Kerusakan Komputer

2. Gejala Pada komputer

3. Solusi

Ketiga data yang telah dikumpulkan diatas kemudian dijadikan fitur-fitur untuk masing-masing kasus yang ada. Hal ini dilakukan untuk mempermudah penyimpanan dan penarikan data pada basis kasus yang dibentuk. Fitur- fitur tersebut yang akan dijadikan input dan output pada sistem [10].

\section{Metodologi PenELITIAN}

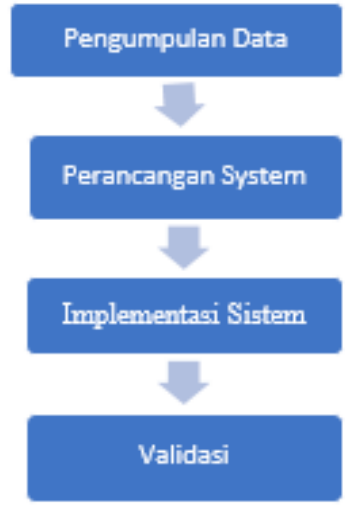

Gbr. 1 Langkah Penelitian

Metodologi penelitian yang digunakan dalam penelitian ini ditunjukkan pada Gbr. 2.

\section{A. Pengumpulan Data}

Untuk mengumpulkan data dalam penelitian ini, metode yang digunakan antara lain :

\section{1) Kuisioner}

Teknik ini merupakan teknik pengumpulan data yang dilakukan melalui daftar pertanyaan sesuai data yang dibutuhkan peneliti untuk kemudian dijawab oleh responden yang relevan. Daftar pertanyaan yang dimuat pada kuisioner ini berisikan gejala kerusakan yang pernah dialami oleh beberapa orang. Sehingga data ini digunakan sebagai data test (kasus baru) yang akan dilakukan pengujian kedalam sistem.

\section{2) Studi Pustaka}

Selain melalui kuisioner, penelitian ini juga menggunakan metode studi pustaka, yakni dengan mengumpulkan pengetahuan dari jurnal, buku, rekaman dan dari sumber lainnya sesuai kebutuhan. Pustaka yang dibutuhkan meliputi konsep CBR, metode SMC, dan kerusakan computer

\section{B. Perancangan Sistem}

Langkah selanjutnya yang dilakukan adalah merancang sistem agar memudahkan dalam tahap implmentasi nantinya. Proses perancangan akan menghasilkan beberapa diagram, diantaranya use case, sequence, dan activity diagram.

\section{1) Use Case Diagram}

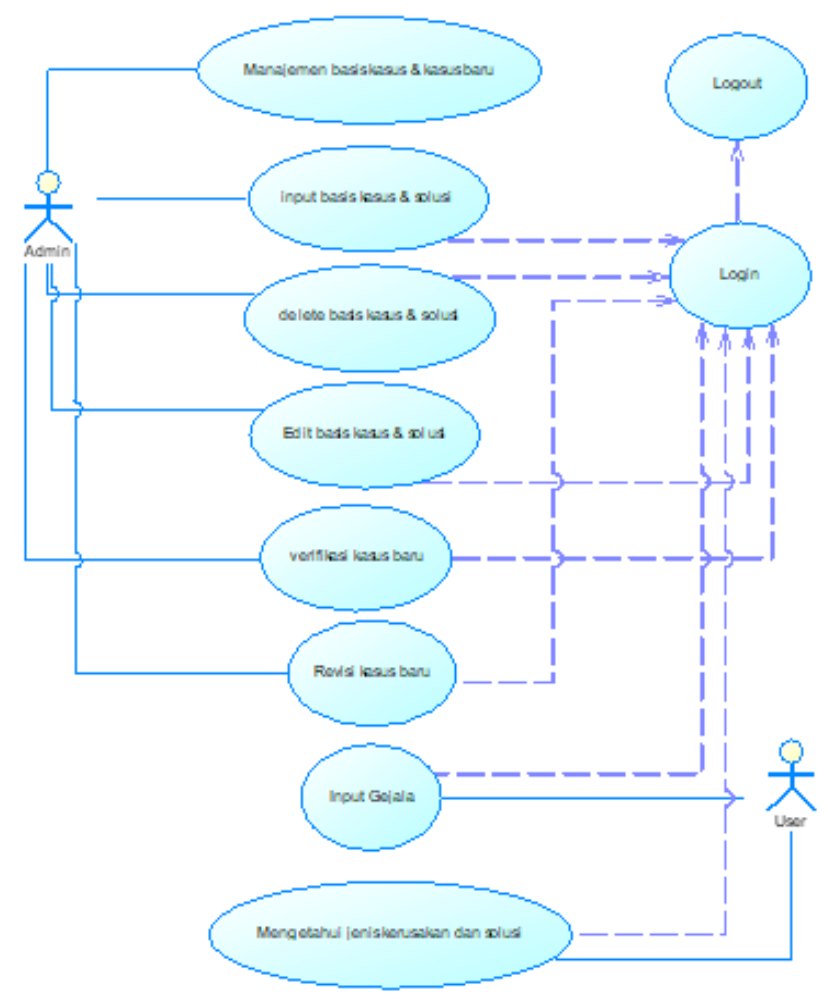

Gbr. 3 Use Case Diagram 
Diagram pertama yang dirancang pada penelitian ini adalah Use Case Diagram. Use Case Diagram merupakan diagram yang menunjukkan gambaran atau representasi hubungan entitas luar (aktor) dengan sistem atau dengan kata lain melalui Use Case Diagram maka dapat dilihat interaksiatau fitur-fitur yang dapat dilakukan oleh masingmasing pengguna (aktor) yang terlibat pada sistem. Use Case Diagram pada Gbr. 3 menunjukan proses dari admin dan user untuk memaparkan apa saja yang dilakukan oleh penggunan pada sistem. Setelah beberapa tindakan yang dilakukan pengguna berikutnya adalah penjabaran Sequence diagram.

\section{2) Sequence Diagram}

Sequnce Diagram pada Gbr. 4 menunjukkan alur input gejala yang dilakukan user di dalam sistem. Untuk dapat melakukan deteksi kerusakan komputer, user diharuskan memasukkan gelaja kerusakan yang terjadi pada komputernya masing-masing melalui form yang tersedia pada sistem.

Setelah user memasukkan gejala-gejala tersebut maka sistem akan melakukan komputasi untuk mencari kasus lampau yang memiliki kemiripan paling tinggi dengan kasus yang dimasukkan oleh user menggunakan metode SMC. Hasil diagnosis pada kasus dengan kemiripan tertinggi tersebut akan dijadikan solusi atas kerusakan yang terjadi pada kasus baru.

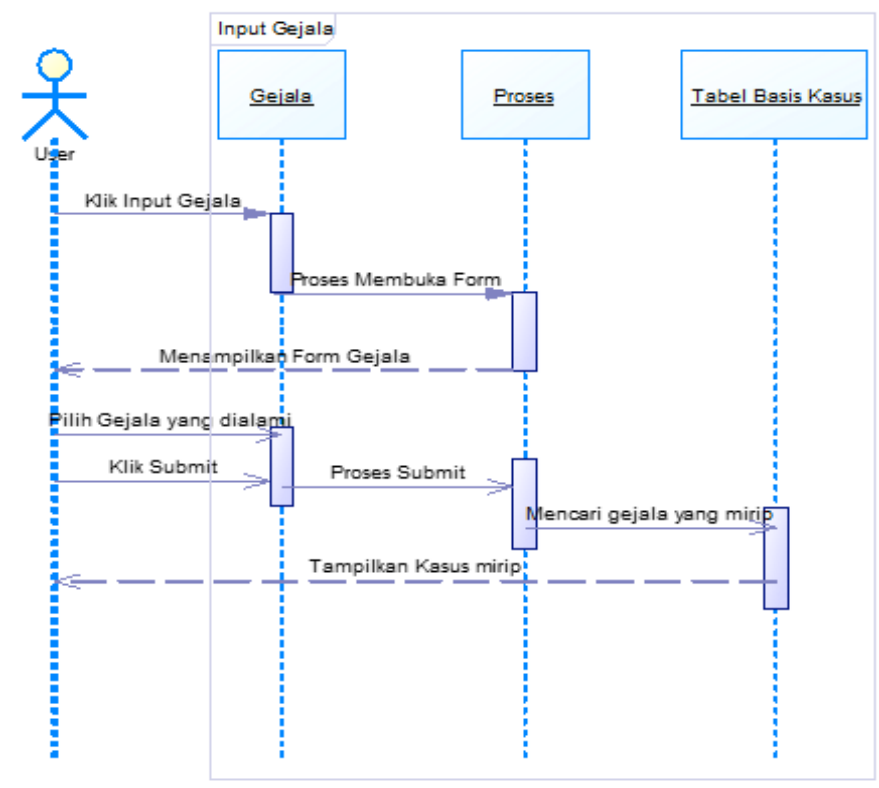

Gbr. 4 Sequence Diagram

\section{3) Activity Diagram}

Gbr. 5 merupakan sequence diagram pada proses utama sistem yang dibuat. Untuk dapat melakukan proses idemtifikasi, maka pengguna diwajibkan untuk memasukkan gejala kerusakan yang terjadi pada komputer. Setelah gejala dimasukkan maka sistem akan melakukan komputasi mencari nilai kemiripan (similaritas) yang paling tinggi sebagai hasil diagnosis sistem.

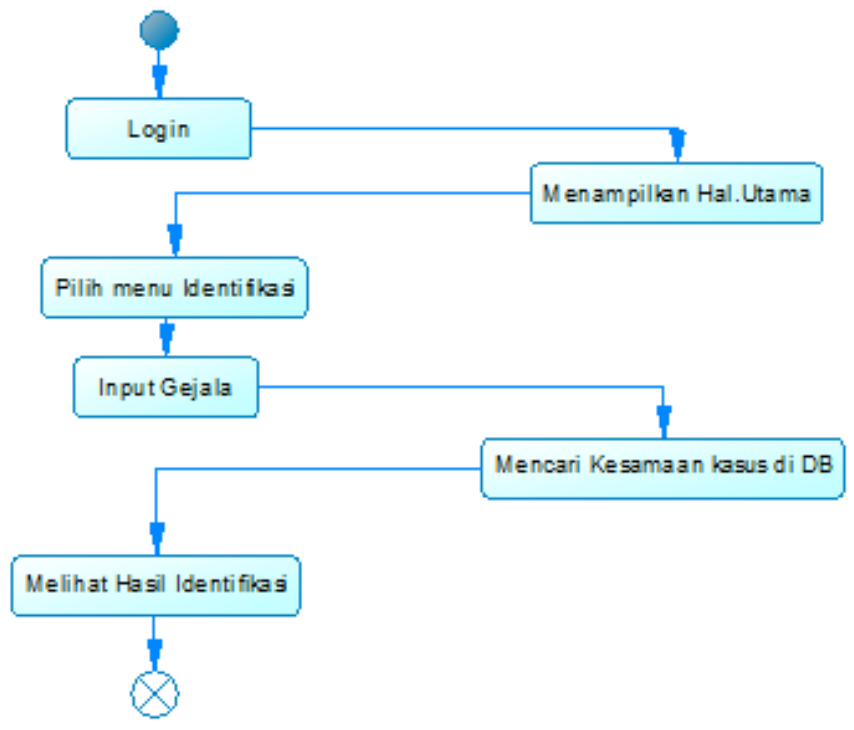

Gbr. 5 Activity Diagram

\section{Implementasi Sistem}

Terdapat 2 jenis pengguna pada sistem yang dibangun, yakni admin yang dapat mengakses keseluruhan fitur yang terdapat pada sistem CBR, serta pengguna biasa atau user. Adapaun fitur-fitur yang dapat diakses oleh admin diantaranya menambahkan pengguna baru, memasukan dan merevisi kasus hasil identifikasi kerusakan serta menyimpan kasus baru. Sedangkan pengguna hanya dapat melakukan proses diagnosis kerusakan dengan memasukkan gejala-gejala yang dialami komputernya untuk kemudian diidentifikasi dan diberikan solusinya [1].

Pada Proses implementasi bahan dan alat yang digunakan dalam membangun sistem tersebut, sebagai berikut:

1) Bahan

- Bahasa pemrograman yang digunakan adalah PHP

- Editor yang digunakan adalah Sublime

- Basis kasus disimpan menggunakan phpmyadmin.

2) Alat

- Sistem operasi menggunakan Windows 10 Ultimate 64-bit

- Prosesor yang tertanam pada komputer adalah Intel Core i5-825U CPU @ 3.40 GHz

\section{HASIL DAN PEMBAHASAN}

Setelah proses perancangan selesai dilakukan, maka langkah selanjutnya adalah mengimplementasikan hasil rancangan menjadi sebuah sistem menggunakan bahasa pemrograman PHP. 


\section{A. Pangisian Basis Kasus}

Dalam tahapan pengisian basis kasus terdapat 40 kasus dengan 16 gejala dan 5 jenis kerusakan. Data yang digunakan merupakan kumpulan Data set yang didapat dari situs website yang mememiliki data mengenai macam-macam kerusakan dan solusi. Data test diperoleh dari penyebaran kuisioner pada mahasiswa yang akan dijadikan data uji sebagai kasus baru. Pada pengisisan basis kasus ini akan diinputkan oleh admin kedalam sistem.

\section{B. Proses Identifikasi Kerusakan}

Sistem melakukan proses identifikasi dengan memperhatikan faktor gejala. Proses identifikasi dimulai dengan menginputkan data gejala yang dialami seorang pasien, kemudian sistem melakukan proses retrieve dan menghitung tingkat kemiripan menggunakan metode simple matching coefficient (SMC). Flowchart sistem dalam proses identifikasi kerusakan seperti pada Gbr. 6.

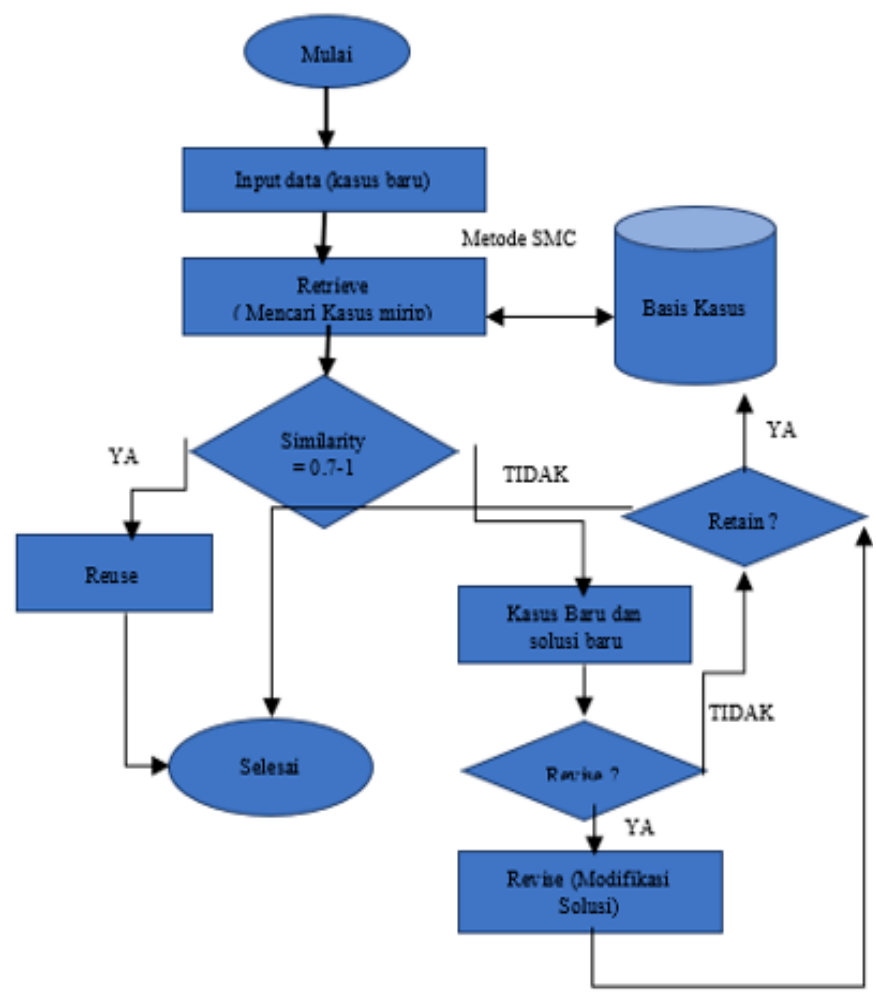

Gbr. 6 Flowchart Sistem

\section{Hasil Identifikasi Kerusakan dan Perancangan Sistem}

Pada tahap perancangan sistem, interface merupakan tampilan yang memudahkan user untuk memahami penggunaan dari sitem tersebut. Berikut beberapa tampilan yang ada pada sistem :

\section{1) Menu Identifikasi Kerusakan}

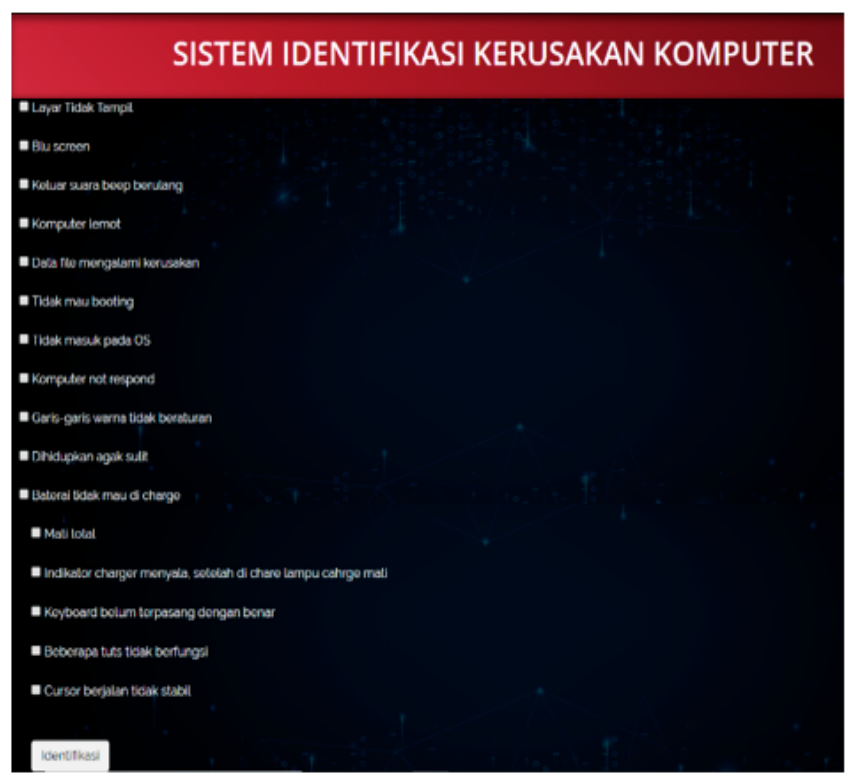

Gbr. 7 Menu Identifikasi Kerusakan

\section{2) Halaman Hasil Identifikasi Kerusakan}

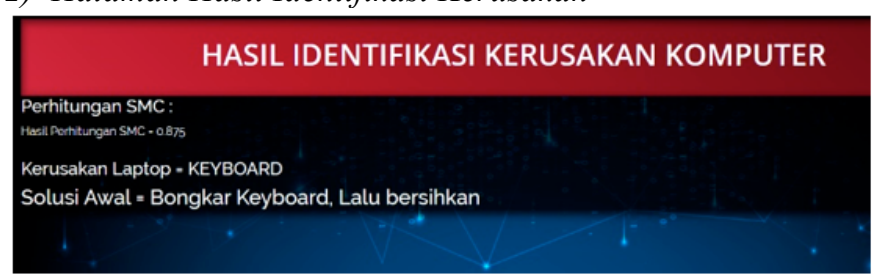

Gbr. 8 Halaman Hasil Identifikasi

Pada tahap identifikasi kerusakan ini setiap kasus baru akan dihitung tingkat kemiripanya dengan kasus lama berdasarkan kemunculan gejala dengan perhitungan similaritas dilakukan pada setiap kasus yang memiliki kesamaan fitur dengan kasus baru, kemudian memilih kasus dengan kemiripan tertinggi sebagai solusi. Berikut contoh perhitungan similaritas dengan metode SMC secara manual seperti pada Tabel I.

$$
\text { 1. } \begin{aligned}
\operatorname{SMC}(\mathrm{K} 01, \mathrm{~N} 01) & =\frac{2+12}{1+1+2+12} \\
& =0.875 \\
\text { 2. } \operatorname{SMC}(\mathrm{K} 02, \mathrm{~N} 01) & =\frac{0+7}{6+3+0+7} \\
& =0.4375
\end{aligned}
$$

Berdasarkan hasil perhitungan similaritas kasus baru terhadap kasus lama yang terdapat pada basis kasus (K01 dan $\mathrm{K} 02$ ), nilai kemiripan pada kasus $\mathrm{K} 01=0.875$, lebih besar dari pada kasus K02 $=0.4375$. Sehingga dapat disimpulkan bahwa kasus K01 adalah kasus yang paling mirip dengan kasus baru. 
Hasil proses identifikasi meliputi proses input gejala kerusakan komputer, pencarian kasus terdahulu yang mirip dengan kasus baru (retrieve), menghitung tingkat kemiripan (similaritas) dengan metode SCM dan menyimpulkan hasil identifikasi berdasarkan nilai kemiripan paling tinggi sehingga bisa didapat output mengenai jenis kerusakan apa dan solusinya.

TABEL I

CONTOH BASIS KaSUS

\begin{tabular}{|c|c|c|c|c|}
\hline \multirow{2}{*}{ No } & \multirow{2}{*}{ Data Kasus } & \multicolumn{2}{|c|}{ Basis Kasus } & \multirow{2}{*}{$\begin{array}{r}\begin{array}{r}\text { Kasus } \\
\text { Baru }\end{array} \\
\mathrm{N} 01\end{array}$} \\
\hline & & K01 & K02 & \\
\hline A. & GEJALA & & & \\
\hline 1. & $\begin{array}{l}\text { Layar Tidak } \\
\text { Tampil }\end{array}$ & 0 & 0 & 0 \\
\hline 2. & Blu screen & 0 & 1 & 0 \\
\hline 3. & $\begin{array}{l}\text { Keluar suara beep } \\
\text { berulang }\end{array}$ & 0 & 0 & 0 \\
\hline 4. & Komputer lemot & 0 & 1 & 0 \\
\hline 5. & $\begin{array}{l}\text { Data file } \\
\text { mengalami } \\
\text { kerusakan }\end{array}$ & 0 & 1 & 0 \\
\hline 6. & Tidak mau booting & 0 & 1 & 0 \\
\hline 7. & $\begin{array}{l}\text { Tidak masuk pada } \\
\text { OS }\end{array}$ & 0 & 1 & 0 \\
\hline 8. & $\begin{array}{l}\text { Komputer not } \\
\text { respond }\end{array}$ & 0 & 1 & 0 \\
\hline 9. & $\begin{array}{l}\text { Garis-garis warna } \\
\text { tidak beraturan }\end{array}$ & 0 & 0 & 0 \\
\hline 10. & $\begin{array}{l}\text { Dihidupkan agak } \\
\text { sulit }\end{array}$ & 0 & 0 & 0 \\
\hline 11. & $\begin{array}{l}\text { Baterai tidak mau } \\
\text { di charge }\end{array}$ & 0 & 0 & 0 \\
\hline 12. & Mati total & 0 & 0 & 0 \\
\hline 13. & $\begin{array}{l}\text { Indikator charger } \\
\text { menyala, setelah di } \\
\text { chare lampu } \\
\text { cahrge mati }\end{array}$ & 0 & 0 & 1 \\
\hline 14. & $\begin{array}{l}\text { Keyboard belum } \\
\text { terpasang dengan } \\
\text { benar }\end{array}$ & 1 & 0 & 1 \\
\hline 15. & $\begin{array}{l}\text { Beberapa tuts tidak } \\
\text { berfungsi }\end{array}$ & 1 & 0 & 0 \\
\hline 16. & $\begin{array}{l}\text { Cursor berjalan } \\
\text { tidak stabil }\end{array}$ & 1 & 0 & 1 \\
\hline
\end{tabular}

\begin{tabular}{|l|l|l|l|l|}
\hline B. & $\begin{array}{l}\text { JENIS } \\
\text { KERUSAKAN }\end{array}$ & (KEYBOARD) & (HARDDISK) & $?$ \\
\hline C. & SOLUSI & S01 & S02 & $?$ \\
\hline
\end{tabular}

\section{Kesimpulan}

Berdasarkan hasil pembahasan yang telah dilakukan, maka dapat disimpulkan bahwa :

1. Sistem yang akan dirancang dapat membantu user dalam mengidentifikasi kerusakan awal pada komputer.

2. Sistem ini mampu memberikan informasi kepada user mengenai jenis kerusakan komputer berdasarkan gejala, beserta solusinya.

\section{REFERENSI}

[1] E. Faizal, "Case Based Reasoning Diagnosis Penyakit Cardiovascular Dengan Metode Simple Matching Coefficient Similarity," J. Teknol. Inf. dan Ilmu Komput., 2014, doi: 10.25126/jtiik.201412116.

[2] Annisa, Turnisa, and H. S. Pratiwi, "Diagnosis Kerusakan Komputer Menggunakan Metode Similarity Jaccard Coeficient," vol. 1, no. 2, 2017.

[3] S. Mulyana; and S. Hartati, "Tinjauan Singkat Perkembangan CaseBased Reasoning," in Seminar Nasional Informatika 2009 (Semnasif 2009) Upn "Veteran" Yogyakarta, 2009.

[4] A. A. Amran, "Implementasi Metode Penalaran Case-Based Reasoning dengan Algoritma Nearest Neighbor dalam Identifikasi Kerusakan Laptop," Universitas Sanata Dharma, 2018.

[5] Filiyensi, "Perbandingan Akurasi Metode Case Based Reasoning (CBR)-Simple Matching Coefficient (Smc) dan Case Based Reasoning (CBR)-Jaccard Coefficient (Jc) Untuk Mendiagnosa Penyakit Tanaman Padi," Universitas Islam Negeri Sultan Syarif Kasim Riau, 2018.

[6] A. Nur, J. Asahar, and D. I Wayan, "Implementasi Metode Case Based Reasoning ( CBR ) Dalam Menentukan Klasifikasi Anak Yang Mengalami Reterdasi Mental," Rekursif, vol. 5, no. 1, pp. 33-42, 2017.

[7] N. L. P. Merawati; and S. Hartati, "Sistem Rekomendasi Topik Skripsi Menggunakan Metode Case Based Reasoning," J. Ilm. Teknol. Inf. Terap., vol. 4, no. 3, 2018.

[8] A. Aamodt and E. Plaza, Case-based Reasoning : foundation issues, methodological variation and System approach, Vol 7: 1. IOS Press, 1994.

[9] R. Sari; Tursina; and A. S. Sukamto, "Pemilihan Resep Masakan Berdasarkan Ketersediaan Bahan Masakan Dengan Metode Simple Matching Coefficient (Smc)," Jepin (Jurnal Edukasi Dan Penelit. Inform., vol. 5, no. 1, 2019.

[10] Tursina, "Case Base Reasoning Untuk Menentukan Daerah Menentukan Daerah Berpotensi Demam Berdarah ( Studi Kasus Kota Pontianak )," Sembistek, pp. 534-543, 2014. 